\title{
Atmospheric mercury in the Southern Hemisphere - Part 1: Trend and inter-annual variations in atmospheric mercury at Cape Point, South Africa, in 2007-2017, and on Amsterdam Island in 2012-2017
}

Franz Slemr et al.

Correspondence to: Franz Slemr (franz.slemr@mpic.de) and Lynwill Martin (lynwill.martin@weathersa.co.za)

The copyright of individual parts of the supplement might differ from the CC BY 4.0 License. 


\section{Supporting information}

2 Table SI1: Trends at Cape Point for the 2007-2014 period.

\begin{tabular}{|l|l|l|l|l|}
\hline Species & Monthly & Annual slope & Unit & $\mathrm{R}, \mathrm{n}$, significance \\
\hline \multirow{3}{*}{$\mathrm{GEM}$} & average & $16.91 \pm 3.60$ & \multirow{2}{*}{$\mathrm{pg} \mathrm{m}^{-3} \mathrm{yr}^{-1}$} & $0.4436,92,>99.9 \%$ \\
\cline { 2 - 3 } & median & $16.18 \pm 3.61$ & & $0.4273,92,>99.9 \%$ \\
\hline \multirow{2}{*}{$\mathrm{CO}_{2}$} & average & $2.072 \pm 0.025$ & \multirow{2}{*}{$\mathrm{ppm} \mathrm{yr}^{-1}$} & $0.9932,96,>99.9 \%$ \\
\cline { 2 - 3 } & median & $2.080 \pm 0.020$ & & $0.9953,96,>99.9 \%$ \\
\hline \multirow{2}{*}{$\mathrm{Rn}$} & average & $-7.91 \pm 12.76$ & \multirow{2}{*}{$\mathrm{mBq} \mathrm{m}^{-3} \mathrm{yr}^{-1}$} & $-0.0641,95, \mathrm{~ns}$ \\
\cline { 2 - 3 } & median & $-6.77 \pm 7.03$ & & $-0.0994,95, \mathrm{~ns}$ \\
\hline $\mathrm{CO}$ & average & $-1.152 \pm 0.500$ & \multirow{2}{*}{$\mathrm{ppb} \mathrm{yr}^{-1}$} & $-0.2313,96,>95 \%$ \\
\cline { 2 - 3 } & median & $-0.500 \pm 0.356$ & & $-0.1434,96, \mathrm{~ns}$ \\
\hline $\mathrm{CH}_{4}$ & average & $5.698 \pm 0.659$ & \multirow{2}{*}{$\mathrm{ppb} \mathrm{yr}^{-1}$} & $0.6655,96,>99.9 \%$ \\
\cline { 2 - 3 } & median & $5.849 \pm 0.534$ & & $0.7490,96,>99.9 \%$ \\
\hline $\mathrm{O}_{3}$ & average & $0.157 \pm 0.236$ & $\mathrm{ppb} \mathrm{yr}$ & $0.0685,96, \mathrm{~ns}$ \\
\cline { 2 - 3 } & median & $0.152 \pm 0.253$ & & $0.0620,96, \mathrm{~ns}$ \\
\hline
\end{tabular}




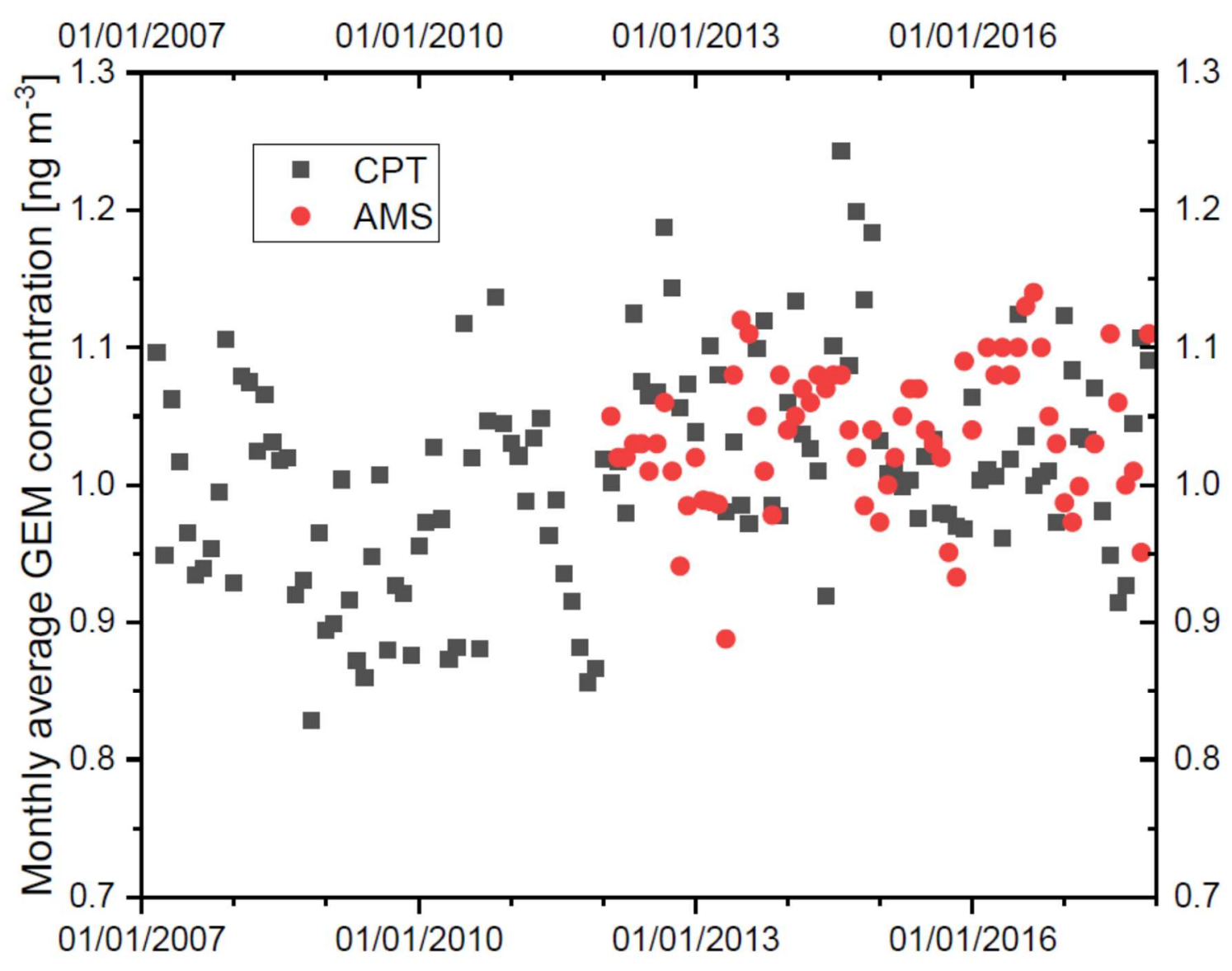

Date

Figure SI1: Monthly median GEM concentrations at Cape Point (CPT) since March 2007 until December 102017 and at Amsterdam Island (AMS) since February 2012 until December 2017. Months with data 11 coverage of less than $10 \%$ were not considered. 